\title{
Association between erythrocyte parameters and metabolic syndrome in urban Han Chinese: a longitudinal cohort study
}

Shuo $\mathrm{Wu}^{1 \dagger}$, Haiyan Lin ${ }^{1 \dagger}$, Chengqi Zhang ${ }^{2}$, Qian Zhang ${ }^{1}$, Dongzhi Zhang ${ }^{3}$, Yongyuan Zhang ${ }^{1}$, Wenjia Meng ${ }^{1}$,

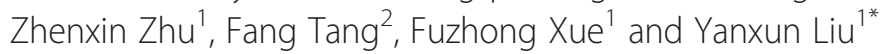

\begin{abstract}
Background: Although various cross-sectional studies have shown that erythrocyte parameters, including red blood cell (RBC), hemoglobin ( $\mathrm{Hb})$ and hematocrit $(\mathrm{HCT})$, were linked with metabolic syndrome (MetS), few longitudinal studies have been used to confirm their relationship. The study, therefore, constructed a large-scale longitudinal cohort in urban Chinese population to highlight and confirm the association between erythrocyte parameters and MetS/its components.
\end{abstract}

Methods: A longitudinal cohort with 6,453 participants was established based on the routine health check-up systems to follow up MetS, and Generalized Estimating Equation (GEE) model was used to detect the association between erythrocyte parameters and MetS/its components (obesity, hyperglycemia, dyslipidemia, and hypertension).

Results: 287 MetS occurred over the four-year follow-up, leading to a total incidence density of 14.19 per 1,000 person-years (287/20218 person-years). Both RBC and $\mathrm{Hb}$ were strongly associated with MetS (RR/95\% Cl, P value; 3.016/1.525-5.967, 0.002 for RBC; 3.008/1.481-6.109, 0.002 for Hb), with their dose-response trends detected. All three erythrocyte parameters (RBC, Hb and $\mathrm{HCT}$ ) were found to be associated with obesity, hypertension and dyslipidemia with similar dose-response trends respectively, while only Hb showed a significant association with hyperglycemia.

Conclusions: Elevated erythrocyte parameters were confirmed to be associated with MetS/its components in urban Chinese population, suggesting that erythrocyte parameters might be served as a potential predictor for risk of MetS.

Keywords: Metabolic syndrome (MetS), Erythrocyte parameters, Longitudinal cohort study, Generalized estimated equation (GEE)

\section{Background}

The metabolic syndrome (MetS) is characterized by obesity, hyperglycemia, dyslipidemia, hypertension and insulin resistance (IR) [1,2]. Various cross-sectional studies have demonstrated that erythrocyte parameters, including red blood cell (RBC), hemoglobin $(\mathrm{Hb})$ and hematocrit $(\mathrm{HCT})$, were associated with MetS [2-8]. These cross-sectional studies showed that elevated RBC was associated with MetS in Taiwan [2], Israel [3], Korea [4], Japan [5,6], Hb in Thailand [7] and Japan [6], HCT in Thailand [7] and

\footnotetext{
* Correspondence: liu-yx@sdu.edu.cn

${ }^{\dagger}$ Equal contributors

'Department of Epidemiology and Biostatistics, School of Public Health, Shandong University, Jinan 250012, China

Full list of author information is available at the end of the article
}

Japan $[6,8]$. These positive associations were further detected in an Ethiopian cohort [9]. Furthermore, in a Japanese cohort [10], HCT was reported to be positively associated with insulin resistance, which is the basic pathogenesis for MetS. As most current results were reported from crosssectional studies, and few from cohort studies, further longitudinal cohort studies are required to confirm the assumption in different populations.

The study, we established a longitudinal cohort with 6,453 participants based on the routine health check-up systems in urban Chinese population to follow up MetS, and each individual in this cohort was undergone at least three repeated health checks in the five years (January 2005 to January 2010). Furthermore, Generalized Estimating Equation (GEE) model, which could handle the repeat 
measurement data with high autocorrelation in the framework of logistic regression model [11-14], was used to detect the association between erythrocyte parameters and MetS/its components (obesity, hyperglycemia, dyslipidemia, and hypertension).

\section{Methods}

\section{Study population}

A large scale longitudinal cohort was set up in 2005 on middle-to-upper class urban Han Chinese who attended routine health check-up at the Centers for Health Management of Shandong Provincial Hospital and Shandong Provincial Qianfoshan Hospital. Four groups of participants without cerebral infarction, cardiovascular disease, coronary artery bypass surgery, MetS and its single component in their first check-up at the year of 2005, 2006, 2007 and 2008 were included in the baseline of our longitudinal cohort study respectively. Figure 1 showed the total of 6453 participants having at least three repeated health check-up within five years (January 2005 to January 2010), and the samples of repeated surveys each year.

All individuals in the longitudinal cohort underwent a general health questionnaire, anthropometric measurements, and laboratory tests. The general health questionnaire covered the current status of smoking, alcohol intake, diet, sleeping quality and physical activity. Anthropometric measurements involved height, weight, and blood pressure. Both height and weight were measured with light clothing without shoes. Body mass index (BMI) was calculated as weight/height ${ }^{2}\left(\mathrm{~kg} / \mathrm{m}^{2}\right)$ as an evidence of obesity. Blood pressure was measured using Omron HEM-907 by the cuff-oscillometric method on the right arm in sitting position after a 5-min rest, and the mean systolic and diastolic blood pressure values of two measurements were recorded respectively. While the participant was fasting, a venous blood sample was taken for laboratory test. Laboratory tests included RBC, $\mathrm{Hb}, \mathrm{HCT}$, white blood count (WBC), platelet distribution width (PDW), mean platelet volume (MPV), thrombocytocrit (PCT), glucose, total cholesterol (CHOL), low-density lipoprotein (LDL), high-density lipoprotein (HDL), triglycerides (TG), gamma-glutamyl transpeptidase (GGT), serum albumin (ALB), serum globulins (GLO), blood urea nitrogen (BUN), and serum creatinine ( $\mathrm{SCr}$ ), etc. This study was approved by the Ethics Committee of School of Public Health, Shandong University, and all participants were given informed written consent.

\section{Definition of the metabolic syndrome}

Considering the target population was Chinese with their specific physiological characteristics, Diabetes Branch of the Chinese Medical Association (CDS) [15] was used as the MetS diagnostic criteria, which is very popular for the Chinese population in clinical practice. MetS was defined as presence of three or more of the following four medical conditions: 1) overweight or obesity, i.e. $\mathrm{BMI} \geq 25.0 \mathrm{Kg} / \mathrm{m}^{2}$; 2) hypertension, i.e. systolic blood pressure $(\mathrm{SBC}) \geq 140 \mathrm{mmHg}$, or diastolic blood pressure $(\mathrm{DBP}) \geq 90 \mathrm{mmHg}$, or previously diagnosed; 3) dyslipidemia, i.e., fasting $\mathrm{TG} \geq 1.7 \mathrm{mmol} / \mathrm{L}$, or fasting HDL $<0.9 \mathrm{mmol} / \mathrm{L}$; 4) hyperglycemia, i.e. fasting bloodglucose $($ FPG) $\geq 6.1 \mathrm{mmol} / \mathrm{L}$, or $2 \mathrm{~h}$ Post-meal Glucose (PG) $\geq 7.8 \mathrm{mmol} / \mathrm{L}$, or previously diagnosed.

\section{Statistical analysis}

To account for missing values, multiple imputation was performed. Since imputation method was depended on

\begin{tabular}{|c|c|c|c|c|c|}
\hline & $\begin{array}{l}\text { the } 1 \text { st } \\
\text { survey }\end{array}$ & $\begin{array}{l}\text { the } 2 \text { nd } \\
\text { survey }\end{array}$ & $\begin{array}{l}\text { the 3rd } \\
\text { survey }\end{array}$ & $\begin{array}{l}\text { the } 4 \text { th } \\
\text { survey }\end{array}$ & $\begin{array}{l}\text { the } 5 \text { th } \\
\text { survey }\end{array}$ \\
\hline 2005 & 1562 & $\begin{array}{c}890 \\
(56.98 \%) \\
\end{array}$ & $\begin{array}{c}1336 \\
(85.53 \%)\end{array}$ & $\begin{array}{c}1176 \\
(75.29 \%)\end{array}$ & \begin{tabular}{c|c|}
1327 \\
$(84.96 \%)$
\end{tabular} \\
\hline 2006 & 3145 & \begin{tabular}{|c|}
2741 \\
$(87.15 \%)$ \\
\end{tabular} & $\begin{array}{c}2721 \\
(86.52 \%) \\
\end{array}$ & \begin{tabular}{|c|}
2596 \\
$(82.54 \%)$ \\
\end{tabular} & \begin{tabular}{|c|}
2019 \\
$(64.20 \%)$ \\
\end{tabular} \\
\hline 2007 & 1286 & $\begin{array}{c}1209 \\
(94.01 \%) \\
\end{array}$ & $\begin{array}{c}1215 \\
(94.48 \%) \\
\end{array}$ & \begin{tabular}{|c|}
770 \\
$(59.88 \%)$ \\
\end{tabular} & \\
\hline 2008 & 460 & $\begin{array}{c}460 \\
(100.00 \% \\
\end{array}$ & $\begin{array}{c}460 \\
(100.00 \%)\end{array}$ & & \\
\hline total & 6453 & \begin{tabular}{|c|}
5300 \\
$(82.13 \%)$ \\
\end{tabular} & \begin{tabular}{|c|}
5732 \\
$(88.83 \%)$ \\
\end{tabular} & \begin{tabular}{|c|}
4542 \\
$(70.39 \%)$ \\
\end{tabular} & \begin{tabular}{|c|}
3346 \\
$(51.85 \%)$ \\
\end{tabular} \\
\hline
\end{tabular}


the patterns of the missing data and the types of the imputed variables, without loss of generality, the Markov chain Monte Carlo (MCMC) method was chosen according to MI Procedure of SAS 9.1.3 [16]. Most variables had less than $2 \%$ missing observations before imputation except diet, drinking, smoking, quality of sleep and physical activity having less than $10 \%$ missing values. The original continuous erythrocyte parameters were categorized into 4 levels (Q1-Q4) using the 3 quartiles of P25, P50 and P75 as critical values, with $\leq$ P25 for $\mathrm{Q} 1,>\mathrm{P} 25$ and $\leq \mathrm{P} 50$ for $\mathrm{Q} 2,>\mathrm{P} 50$ and $\leq \mathrm{P} 75$ for $\mathrm{Q} 3$, and $>$ P75 for Q4 respectively. Summary statistics were used to illustrate the distribution characteristics for variables of interest at each repeated surveys, and student's $t$ test for continuous variables and chi-square test for categorical variables were used to detect the statistical significances compared with the first survey (baseline). As GEE model could handle the repeat measurement data with high autocorrelation in the framework of logistic regression model [11-14], it was used to detect the association between erythrocyte parameters and MetS/ its components. Simple GEE model was firstly used to select variables associated with MetS/its components, then variables which were significant at the level of 0.05 in the simple GEE analysis entered the multiple GEE model to adjust the potential confounding. The 'Logit' link function was chosen in GEE analysis, with significance level 0.05 . All the statistical analyses were performed on SAS 9.1.3.

\section{Results}

Table 1 summarized the characteristics of erythrocyte parameters levels and other potential confounding factors of the participants at each repeated survey, which showed that most factors were generally higher than that in the first survey (baseline). A total of 294 cases of MetS occurred over the four-year follow-up, leading to a total incidence density of 14.19 per 1,000 person-years (287/20218 person-years). During the follow up, 3 participants were diagnosed as cerebral infarction (personyears), 141 participants were diagnosed as cardiovascular disease (person-years) and no-one underwent coronary artery bypass surgery (see Additional file 1: Table S20).

Table 2 showed the selected variables associated with MetS at $\alpha=0.05$ level. It indicated that each of the 3 erythrocyte parameters (RBC, Hb, and HTC) with 9 potential confounding factors, including gender, age, GGT, GLO, BUN, WBC, diet, drinking and smoking might be linked with MetS. Also, each of the 3 erythrocyte parameters might be linked with the four components of MetS with their specific potential confounding factors respectively (see Additional file 2: Table S1, Additional file 3: Table S2, Additional file 4: Table S3 and Additional file 5: Table S4 for details).
Table 3 illustrated the summarized results of the association analyses between erythrocyte parameters and MetS/its components after adjusting potential confounding factors by multiple GEE model. (Confounding variables were not shown, detailed information seeing Additional file 6: Table S5, Additional file 7: Tables S6, Additional file 8: Table S7, Additional file 9: Table S8, Additional file 10: Table S9, Additional file 11: Table S10, Additional file 12: Table S11, Additional file 13: Table S12, Additional file 14: Table S13, Additional file 15: Table S14, Additional file 16: Table S15, Additional file 17: Table S16, Additional file 18: Table S17, Additional file 19: Table S18 and Additional file 20: Table S19.). It revealed that the top quartiles (Q4) of RBC and $\mathrm{Hb}$ were strongly associated with MetS (RR/95\%CI, P value; 3.016/1.5255.967, 0.002 for RBC; 3.008/1.481-6.109, 0.002 for $\mathrm{Hb}$ ) using Q1 as reference level. Although no significant for Q2 and Q3, trends of increased of RR were observed from Q2 to Q4, indicating that there were dose-response trends between the 2 erythrocyte parameters and MetS. In addition, all three erythrocyte parameters (RBC, $\mathrm{Hb}$ and HCT) were found to be associated with obesity, hypertension and dyslipidemia with similar dose-response trends respectively, while only $\mathrm{Hb}$ showed a significant association with hyperglycemia.

\section{Discussions}

This study mainly attempted to confirm the association between erythrocyte parameters and MetS/its components using the longitudinal cohort. Although the longitudinal cohort study was based on routine health check-up in urban Han Chinese population from middle to upper socioeconomic strata, the positive associations between erythrocyte parameters and MetS/its components were observed, which were also detected in other two cohort study [9].

RBC had been reported to be associated with MetS in various populations by cross-sectional studies [2-6] and in Ethiopia by a cohort studies [9]. At present study, we not only confirmed that RBC was associated with MetS and its 3 single components (dyslipidemia, obesity and hypertension), but also observed the dose-response trends (seeing Table 3 or Additional file 7: Table S6, Additional file 8: Tables S7 and Additional file 9: Table S8). These results highlighted the positive association between $\mathrm{RBC}$ and MetS. In pathogenesis, this linkage might be explained by the insulin resistance(IR) mechanisms in the development of MetS, because insulin and insulin growth factors I and II supporting erythropoiesis in both vitro [17-21] and vivo [22-24] had been detected in laboratory studies.

As another important erythrocyte parameter, $\mathrm{Hb}$ also had been reported to be associated with MetS in Thailand [7] and Japan [6] by Cross-sectional studies, 
Table 1 Distribution of erythrocyte parameters and other potential confounding factors

\begin{tabular}{|c|c|c|c|c|c|}
\hline Variables & $\begin{array}{l}\text { The 1st survey } \\
\qquad(\mathrm{N}=6453)\end{array}$ & $\begin{array}{l}\text { The 2nd survey } \\
\qquad(\mathrm{N}=5300)\end{array}$ & $\begin{array}{l}\text { The 3rd survey } \\
\qquad(\mathrm{N}=5732)\end{array}$ & $\begin{array}{l}\text { The 4th surveys } \\
\qquad(\mathrm{N}=4542)\end{array}$ & $\begin{array}{l}\text { The 5th survey } \\
\qquad(\mathrm{N}=3346)\end{array}$ \\
\hline age & $38.563 \pm 11.444$ & $39.798 \pm 11.572$ & $40.619 \pm 11.406^{*}$ & $42.413 \pm 11.495^{*}$ & $43.317 \pm 11.352^{*}$ \\
\hline \multicolumn{6}{|l|}{ sex } \\
\hline male & 2688 & 2196 & 2415 & 1861 & 1351 \\
\hline female & 3765 & 3104 & 3317 & 2681 & 1995 \\
\hline RBC & $4.769 \pm 0.456$ & $4.705 \pm 0.454^{*}$ & $4.698 \pm 0.454^{*}$ & $4.678 \pm 0.463^{*}$ & $4.7 \pm 0.432^{*}$ \\
\hline $\mathrm{Hb}$ & $142.454 \pm 14.885$ & $142.845 \pm 15.27$ & $141.73 \pm 15.169^{*}$ & $142.569 \pm 15.381$ & $142.115 \pm 16.465$ \\
\hline HCT & $42.888 \pm 3.905$ & $42.408 \pm 3.951^{*}$ & $42.015 \pm 3.889^{*}$ & $42.191 \pm 3.964^{*}$ & $41.846 \pm 3.869^{*}$ \\
\hline GGT & $18.004 \pm 16.393$ & $20.016 \pm 20.032^{*}$ & $19.383 \pm 16.419^{*}$ & $21.08 \pm 20.193^{*}$ & $21.336 \pm 20.323^{*}$ \\
\hline ALB & $46.575 \pm 2.427$ & $45.789 \pm 2.784^{*}$ & $45.362 \pm 2.742^{*}$ & $45.128 \pm 2.69^{*}$ & $44.991 \pm 2.436^{*}$ \\
\hline GLO & $27.016 \pm 3.838$ & $27.133 \pm 3.973$ & $28.253 \pm 3.972^{*}$ & $29.128 \pm 4.046^{*}$ & $30.314 \pm 3.826^{*}$ \\
\hline BUN & $4.746 \pm 1.197$ & $4.698 \pm 1.175^{*}$ & $4.664 \pm 1.154^{*}$ & $4.772 \pm 1.204$ & $4.812 \pm 1.145^{*}$ \\
\hline $\mathrm{S}-\mathrm{Cr}$ & $76.943 \pm 13.736$ & $77.897 \pm 13.842^{*}$ & $77.502 \pm 14.072^{*}$ & $78.587 \pm 14.694^{*}$ & $77.012 \pm 12.743$ \\
\hline WBC & $6.167 \pm 1.466$ & $6.069 \pm 1.483^{*}$ & $6.054 \pm 1.479^{*}$ & $6.142 \pm 1.501$ & $6.182 \pm 1.489$ \\
\hline PDW & $12.346 \pm 1.712$ & $12.323 \pm 1.722$ & $12.226 \pm 1.671^{*}$ & $12.164 \pm 1.669^{*}$ & $12.088 \pm 1.63^{*}$ \\
\hline MPV & $10.454 \pm 0.811$ & $10.448 \pm 0.946$ & $10.42 \pm 0.803^{*}$ & $10.398 \pm 0.802^{*}$ & $10.428 \pm 0.796$ \\
\hline $\mathrm{PCT}$ & $0.247 \pm 0.089$ & $0.257 \pm 0.320^{*}$ & $0.254 \pm 0.266^{*}$ & $0.249 \pm 0.055$ & $0.245 \pm 0.054$ \\
\hline \multicolumn{6}{|l|}{ Diet } \\
\hline Vegetarian & 3454 & $2194^{*}$ & $2098^{*}$ & $1906^{*}$ & $1214^{*}$ \\
\hline normal & 1863 & 792 & 750 & 550 & 463 \\
\hline meat-based & 1118 & 2283 & 2866 & 2064 & 1653 \\
\hline sea food & 18 & 31 & 18 & 22 & 16 \\
\hline \multicolumn{6}{|l|}{ Drinking } \\
\hline no & 3698 & 2959 & 3333 & $2731^{*}$ & 1977 \\
\hline yes & 2755 & 2341 & 2399 & 1811 & 1369 \\
\hline \multicolumn{6}{|l|}{ Smoking } \\
\hline no & 5274 & 4323 & 4678 & 3726 & 2718 \\
\hline yes & 1179 & 977 & 1054 & 816 & 628 \\
\hline \multicolumn{6}{|l|}{ Sleep } \\
\hline$\geq$ fair & 6270 & 5173 & 5557 & $4373^{*}$ & 3250 \\
\hline$<$ fair & 183 & 127 & 175 & 169 & 96 \\
\hline \multicolumn{6}{|l|}{ Exercise } \\
\hline never/seldom & 4694 & 3902 & $4267^{*}$ & $3469^{*}$ & 2477 \\
\hline often & 1759 & 1398 & 1465 & 1073 & 869 \\
\hline
\end{tabular}

*P $<0.05$ compared with the first survey (baseline);

The abbreviations of the variables: $\mathrm{RBC}=$ red blood cell; $\mathrm{Hb}=$ Hemoglobin; $\mathrm{HCT}=$ Hematocrit; $\mathrm{GGT}=$ gamma-glutamyl transpeptidase; $\mathrm{ALB}=$ serum albumin; $\mathrm{GLO}=$ serum globulins; $\mathrm{BUN}=$ blood urea nitrogen; $\mathrm{S}-\mathrm{Cr}=$ serum creatinine; $\mathrm{WBC}=$ white blood cell; $\mathrm{PDW}=\mathrm{Platelet}$ distribution width; $\mathrm{MPV}=$ mean platele volume; PCT = Thrombocytocrit; Diet: 0: Vegetarian, 1: normal, 2: meat-based 3: sea food (the major kinds of food used to have); Drinking: 0: never, 1: seldom, 2: often, wine, 3: often beer, 4: often, Chinese spirits, 5: often, mixed all kinds; Smoking: 0: never, 1: seldom, 2: quit, 3: 1-4/d, 4: 5 -15/d, 5: >15/d; Quality of sleep: 0: excellent, 1: well, 2: fair 3: poor, 4: very poor (evaluated by themselves); Physical activity 0: never, 1: seldom (1-2 times a week), 2 : often or everyday (more than 3 times a week).

as well as in Ethiopia [9] by a cohort study. This positive association was also detected in our longitudinal cohort study with a potential dose-response trend between them (seeing Table 3 or Additional file 11: Table S10, Additional file 12: Table S11, Additional file 13: Table S12, Additional file 14: Table S13 and Additional file 15: Table S14). The possible mechanism might be supported by the following pathogenesis. $\mathrm{Hb}$ is a well recognized carrier and buffer of nitric oxide (NO), and various compounds of $\mathrm{Hb}$ with $\mathrm{NO}$ can affect $\mathrm{Hb}$-oxygen affinity of the whole blood [25]. Disturbed NO synthesis may exert an adverse effect on endothelial dysfunction through the L-arginine- 
Table 2 The association analyses result from simple GEE model (MetS as dependent variable)

\begin{tabular}{|c|c|c|c|c|c|c|c|}
\hline Quartiles & Estimate & ERR & Z & $P>|Z|$ & RR & Lower $95 \%$ confidence limits & Upper $95 \%$ confidence limits \\
\hline \multicolumn{8}{|c|}{ red blood cell } \\
\hline Q4 & 1.284 & 0.244 & 5.271 & $<0.001$ & 3.612 & 2.241 & 5.824 \\
\hline Q3 & 0.602 & 0.261 & 2.308 & 0.021 & 1.825 & 1.095 & 3.042 \\
\hline Q2 & 0.050 & 0.292 & 0.170 & 0.865 & 1.051 & 0.593 & 1.864 \\
\hline Q1 & ref & ref & ref & ref & ref & ref & ref \\
\hline \multicolumn{8}{|l|}{ hemoglobin } \\
\hline Q4 & 1.271 & 0.209 & 6.078 & $<0.001$ & 3.564 & 2.366 & 5.370 \\
\hline Q3 & 0.492 & 0.232 & 2.118 & 0.034 & 1.635 & 1.037 & 2.577 \\
\hline Q2 & 0.251 & 0.240 & 1.045 & 0.296 & 1.285 & 0.803 & 2.056 \\
\hline Q1 & ref & ref & ref & ref & ref & ref & ref \\
\hline \multicolumn{8}{|l|}{ hematocrit } \\
\hline Q4 & 1.005 & 0.210 & 4.776 & $<0.001$ & 2.732 & 1.809 & 4.127 \\
\hline Q3 & 0.406 & 0.234 & 1.736 & 0.083 & 1.500 & 0.949 & 2.371 \\
\hline Q2 & 0.123 & 0.249 & 0.496 & 0.620 & 1.131 & 0.694 & 1.844 \\
\hline Q1 & ref & ref & ref & ref & ref & ref & ref \\
\hline gender & -0.946 & 0.157 & -6.034 & $<0.001$ & 0.388 & 0.286 & 0.528 \\
\hline age & 0.410 & 0.039 & 10.596 & $<0.001$ & 1.507 & 1.397 & 1.625 \\
\hline GGT & 0.012 & 0.002 & 7.235 & $<0.001$ & 1.012 & 1.009 & 1.016 \\
\hline ALB & -0.050 & 0.025 & -1.981 & 0.048 & 0.951 & 0.906 & 0.999 \\
\hline GLO & 0.072 & 0.015 & 4.863 & $<0.001$ & 1.074 & 1.044 & 1.106 \\
\hline BUN & 0.177 & 0.049 & 3.599 & $<0.001$ & 1.193 & 1.084 & 1.314 \\
\hline $\mathrm{S}-\mathrm{Cr}$ & 0.010 & 0.006 & 1.668 & 0.095 & 1.010 & 0.998 & 1.022 \\
\hline WBC & 0.284 & 0.031 & 9.061 & $<0.001$ & 1.328 & 1.249 & 1.412 \\
\hline PDW & 0.005 & 0.042 & 0.119 & 0.905 & 1.005 & 0.926 & 1.091 \\
\hline MPV & -0.093 & 0.094 & -0.983 & 0.326 & 0.912 & 0.758 & 1.096 \\
\hline PCT & -0.588 & 1.229 & -0.478 & 0.632 & 0.555 & 0.050 & 6.176 \\
\hline Diet & 0.223 & 0.073 & 3.049 & 0.002 & 1.250 & 1.083 & 1.442 \\
\hline Drinking & 0.173 & 0.046 & 3.796 & 0.001 & 1.189 & 1.087 & 1.300 \\
\hline Smoking & 0.143 & 0.044 & 3.246 & 0.001 & 1.153 & 1.058 & 1.257 \\
\hline Sleep & 0.109 & 0.076 & 1.432 & 0.152 & 1.115 & 0.961 & 1.294 \\
\hline Exercise & -0.013 & 0.159 & -0.080 & 0.937 & 0.987 & 0.723 & 1.348 \\
\hline
\end{tabular}

NO pathway [26]. Furthermore, endothelial dysfunction was reported to be associated with MetS [27,28]. All these evidences expect the association between $\mathrm{Hb}$ and MetS/its components in population level.

Elevated HCT could increase blood viscosity and peripheral resistance to blood flow, and further contribute to IR [29-31]. Therefore, the association between HCT and MetS/its components should be observed in population level. In this paper, HCT associating with obesity, hypertension and dyslipdemia were all detected in urban Han Chinese population (seeing Table 3 or Additional file 17: Table S16, Additional file 18: Table S17, Additional file 19: Table S18), while no statistical significant association between HCT and MetS/ hyperglycemia was found (seeing Table 3, Additional file 16: Table S15 or Additional file 20: Table S19). Similar results were also observed in Ethiopia [9] and Japan [9] by cohort studies, as well as in Thailand [7] and Japan $[9,11]$ by Cross-sectional studies.

Several limitations of this study must be considered. a) Selection bias might exist due to the samples just from routine health check-up population for middle-toupper class urban Han Chinese. b) Owing to the absence of waist circumference measurement, the diagnostic criteria of MetS was just based on China Diabetes Federation, rather than international standard criteria. 
Table 3 The summary results of the association analyses between erythrocyte parameters and MetS/its components after adjusting potential factors by multiple GEE model

\begin{tabular}{|c|c|c|c|c|c|c|c|c|c|c|c|c|c|c|c|c|}
\hline \multirow[t]{2}{*}{ Parameters } & & \multicolumn{3}{|c|}{ MetS } & \multicolumn{3}{|c|}{ Obesity } & \multicolumn{3}{|c|}{ Hyperglycemia } & \multicolumn{3}{|c|}{ Hypertension } & \multicolumn{3}{|c|}{ Dyslipdemia } \\
\hline & & Estimate & $P>|Z|$ & RR & Estimate & $P>|Z|$ & RR & Estimate & $P>|Z|$ & $\mathbf{R R}$ & Estimate & $P>|Z|$ & RR & Estimate & $P>|Z|$ & RR \\
\hline \multirow[t]{4}{*}{ Red blood cell } & Q4 & 1.104 & 0.002 & 3.016 & 0.474 & $<0.001$ & 1.606 & 0.215 & 0.202 & 1.239 & 0.484 & 0.001 & 1.622 & 0.431 & $<0.001$ & 1.539 \\
\hline & Q3 & 0.523 & 0.081 & 1.688 & 0.364 & 0.001 & 1.439 & 0.075 & 0.606 & 1.078 & 0.271 & 0.042 & 1.312 & 0.251 & 0.002 & 1.285 \\
\hline & Q2 & -0.039 & 0.895 & 0.961 & 0.006 & 0.955 & 1.006 & 0.068 & 0.605 & 1.071 & 0.113 & 0.389 & 1.120 & 0.123 & 0.103 & 1.131 \\
\hline & Q1 & ref & ref & ref & ref & ref & ref & ref & ref & ref & ref & ref & ref & ref & ref & ref \\
\hline \multirow[t]{4}{*}{ Hemolglobin } & Q4 & 1.101 & 0.002 & 3.008 & 0.693 & $<0.001$ & 2.000 & 0.654 & 0.001 & 1.923 & 0.749 & $<0.001$ & 2.114 & 0.536 & $<0.001$ & 1.709 \\
\hline & Q3 & 0.454 & 0.144 & 1.575 & 0.447 & $<0.001$ & 1.564 & 0.519 & 0.001 & 1.680 & 0.390 & 0.006 & 1.477 & 0.254 & 0.003 & 1.289 \\
\hline & Q2 & 0.340 & 0.162 & 1.405 & 0.387 & $<0.001$ & 1.473 & 0.307 & 0.025 & 1.359 & 0.273 & 0.035 & 1.314 & 0.082 & 0.251 & 1.086 \\
\hline & Q1 & ref & ref & ref & ref & ref & ref & ref & ref & ref & ref & ref & ref & ref & ref & ref \\
\hline \multirow[t]{4}{*}{ Hemocrite } & Q4 & 0.583 & 0.079 & 1.792 & 0.362 & 0.009 & 1.436 & 0.028 & 0.874 & 1.029 & 0.368 & 0.021 & 1.445 & 0.257 & 0.009 & 1.293 \\
\hline & Q3 & 0.214 & 0.479 & 1.238 & 0.297 & 0.013 & 1.346 & 0.151 & 0.320 & 1.163 & 0.324 & 0.018 & 1.383 & 0.195 & 0.018 & 1.215 \\
\hline & Q2 & 0.034 & 0.892 & 1.035 & 0.220 & 0.028 & 1.246 & 0.014 & 0.915 & 1.014 & 0.149 & 0.250 & 1.161 & 0.003 & 0.969 & 1.003 \\
\hline & Q1 & ref & ref & ref & ref & ref & ref & ref & ref & ref & ref & ref & ref & ref & ref & ref \\
\hline
\end{tabular}


c) The medication history and menstrual history of participants might be significant confounding factors, but they were absent in our database. d) Hematological parameter categories were based on a single assessment of blood, which may cause a misclassification bias. It is, therefore, desired to conduct a perfect longitudinal cohort study in general population for further highlighting the association between erythrocyte parameters and MetS.

\section{Conclusion}

In conclusion, elevated erythrocyte parameters were confirmed to be associated with MetS/its components in urban Chinese population, suggesting that erythrocyte parameters might be a potential predictor for risk of MetS.

\section{Additional files}

Additional file 1: Table S20. The morbidity number of repeated

surveys at each year.

Additional file 2: Table S1. The association analyses result from simple GEE model (obesity as dependent variable).

Additional file 3: Table S2. The association analyses result from simple GEE model (dyslipidemia as dependent variable).

Additional file 4: Table S3. The association analyses result from simple GEE model (hyperglycemia as dependent variable).

Additional file 5: Table S4. The association analyses result from simple GEE model (hypertension as dependent variable).

Additional file 6: Table S5. Multiple GEE analysis of red blood cell and MetS after adjusting other potential confounding factors.

Additional file 7: Table S6. Multiple GEE analysis of red blood cell and obesity after adjusting other potential confounding factors.

Additional file 8: Table S7. Multiple GEE analysis of red blood cell and hypertension after adjusting other potential confounding factors.

Additional file 9: Table S8. Multiple GEE analysis of red blood cell and dyslipidemia after adjusting other potential confounding factors

Additional file 10: Table S9. Multiple GEE analysis of red blood cell and hyperglycemia after adjusting other potential confounding factors.

Additional file 11: Table S10. Multiple GEE analysis of hemoglobin and MetS after adjusting other potential confounding factors.

Additional file 12: Table S11. Multiple GEE analysis of hemoglobin and obesity after adjusting other potential confounding factors.

Additional file 13: Table S12. Multiple GEE analysis of hemoglobin and hypertension after adjusting other potential confounding factors.

Additional file 14: Table S13. Multiple GEE analysis of hemoglobin and dyslipidemia after adjusting other potential confounding factors.

Additional file 15: Table S14. Multiple GEE analysis of hemoglobin and hyperglycemia after adjusting other potential confounding factors.

Additional file 16: Table S15. Multiple GEE analysis of hematocrit and MetS after adjusting other potential confounding factors.

Additional file 17: Table S16. Multiple GEE analysis of hematocrit and obesity after adjusting other potential confounding factors.

Additional file 18: Table S17. Multiple GEE analysis of hematocrit and hypertension after adjusting other potential confounding factors.

Additional file 19: Table S18. Multiple GEE analysis of hematocrit and dyslipidemia after adjusting other potential confounding factors.

Additional file 20: Table S19. Multiple GEE analysis of hematocrit and hyperglycemia after adjusting other potential confounding factors.

\section{Competing interests}

There is no conflict of interest for any of the authors. All authors had access to the data and were involved in drafting the article and revising it critically for important intellectual content.

\section{Authors' contributions}

In our work, YL, FX and $\mathrm{CZ}$ designed the study and directed its implementation, including quality assurance and control. FT, HL and DZ did the clinical exam and collected the data. QZ, YZ, WM and ZZ helped analyzing the data. SW participated much of the above work and led the writing of the paper. All authors read and approved the final manuscript.

\section{Funding}

This work was supported by grants from the National Nature Science Fund (No. 81273177) of China. The funders had no role in study design, data collection and analysis, decision to publish, or preparation of the manuscript.

\section{Author details}

'Department of Epidemiology and Biostatistics, School of Public Health, Shandong University, Jinan 250012. China. ${ }^{2}$ Health Management Center, Shandong Provincial QianFoShan Hospital, Jinan 250014, China. ${ }^{3}$ Center for Health Management, Provincial Hospital affiliated to Shandong University, Jinan 250012, China.

Received: 23 April 2013 Accepted: 8 October 2013

Published: 21 October 2013

\section{References}

1. Grundy SM, Brewer HB, Cleeman Jl, Smith SC, Lenfant C, Conference P: Definition of metabolic syndrome - Report of the National Heart, Lung, and Blood Institute/American Heart Association Conference on Scientific Issues Related to Definition. Circ 2004, 109(3):433-438

2. Wang Y-Y, Lin S-Y, Liu P-H, Cheung BMH, Lai W-A: Association between hematological parameters and metabolic syndrome components in a Chinese population. J Diabetes Complications 2004, 18(6):322-327.

3. Mardi T, Toker S, Melamed S, Shirom A, Zeltser D, Shapira I, Berliner S, Rogowski O: Increased erythropoiesis and subclinical inflammation as part of the metabolic syndrome. Diabetes Res Clin Pract 2005, 69(3):249-255.

4. Kim JA, Choi YS, Hong Jl, Kim SH, Jung HH, Kim SM: Association of metabolic syndrome with white blood cell subtype and red blood cells (Retracted Article. See vol 53, pg 871, 2006). Endocr J 2006, 53(1):133-139.

5. Kotani K, Sakane N, Kurozawa Y: Increased Red Blood Cells in Patients with Metabolic Syndrome. Endocr J 2006, 53:713-714.

6. Kawamoto R, Tabara Y, Kohara K, Miki T, Kusunoki T, Abe M, Katoh T: Hematological parameters are associated with metabolic syndrome in Japanese community-dwelling persons. Endocrine 2013, 43(2):334-341.

7. Lohsoonthorn V, Jiamjarasrungsi W, Williams MA: Association of hematological parameters with clustered components of metabolic syndrome among professional and office workers in Bangkok, Thailand. Diabetes Metab Clin Res Rev 2007, 1(3):143-149.

8. Sugimori H, Tomoda F, Koike T, Kinuno H, Kurosaki H, Masutani T, Inoue H: Blood Rheology and Platelet Function in Untreated Early-Stage Essential Hypertensives Complicated with Metabolic Syndrome. Int J Hypertens 2012, 2012:1-5.

9. Nebeck K, Gelaye B, Lemma S, Berhane Y, Bekele T, Khali A, Haddis Y, Williams MA: Hematological parameters and metabolic syndrome: Findings from an occupational cohort in Ethiopia. Diabetes Metab Clin Res Rev 2012, 6(1):22-27.

10. Tabara Y, Igase M, Saito I, Nishida W, Kohara K, Sakurai S, Kawamura R, Okada Y, Hitsumoto S, Onuma H, et al: ssociation of hematological parameters with insulin resistance, insulin sensitivity, and asymptomatic cerebrovascular damage: The J-SHIP Toon Health Study. Clin Hemorheol Microcirc 2012. Epub ahead of print.

11. Rochon J: Application of GEE procedures for sample size calculations in repeated measures experiments. Stat Med 1998, 17(14):1643-1658.

12. Lee J-H, Herzog TA, Meade CD, Webb MS, Brandon TH: The use of GEE for analyzing longitudinal binomial data: A primer using data from a tobacco intervention. Addict Behav 2007, 32(1):187-193.

13. Lin $K-C$, Chen $Y-J$, Shyr Y: A nonparametric smoothing method for assessing GEE models with longitudinal binary data. Stat Med 2008, 27(22):4428-4439. 
14. Hubbard AE, Ahern J, Fleischer NL, Van der Laan M, Lippman SA, Jewell N, Bruckner T, Satariano WA: To GEE or Not to GEE Comparing Population Average and Mixed Models for Estimating the Associations Between Neighborhood Risk Factors and Health. Epidemiol 2010, 21(4):467-474.

15. Lu Y-h, Lu J-m, Wang S-y, Li C-I, Liu L-s, Zheng R-p, Tian H, Wang X-I, Yang L-j, Zhang Y-q, et al: Comparison of the diagnostic criteria of metabolic syndrome by International Diabetes Federation and that by Chinese Medical Association Diabetes Branch. Zhonghua yi xue za zhi 2006, 86(6):386-389.

16. Schafer J: Multiple imputation: a primer. Stat Methods Medods Res 1999 8:3-15.

17. Bersch N, Groopman JE, Golde DW: Natural and biosynthetic insulin stimulates the growth of human erythroid progenitors in vitro. J Clin Endocrinol Metab 1982, 55(6):1209-1211.

18. Dainiak N, Kreczko S: Interactions of insulin, insulinlike growth factor II, and platelet-derived growth factor in erythropoietic culture. J Clin Invest 1985, 76(3):1237-1242.

19. Sawada K, Krantz SB, Dessypris EN, Koury ST, Sawyer ST: Human colonyforming units-erythroid do not require accessory cells, but do require direct interaction with insulin-like growth factor I and/or insulin for erythroid development. J Clin Invest 1989, 83(5):1701-1709.

20. Ratajczak J, Zhang Q, Pertusini E, Wojczyk BS, Wasik MA, Ratajczak MZ: The role of insulin (INS) and insulin-like growth factor-I (IGF-I) in regulating human erythropoiesis. Studies in vitro under serum-free conditions - comparison to other cytokines and growth factors. Leuk 1998, 12(3):371-381.

21. Miyagawa S, Kobayashi M, Konishi N, Sato T, Ueda K: Insulin and insulinlike growth factor I support the proliferation of erythroid progenitor cells in bone marrow through the sharing of receptors. $\mathrm{Br} J$ Haematol 2000, 109(3):555-562.

22. Widness JA, Susa JB, Garcia JF, Singer DB, Sehgal P, Oh W, Schwartz R, Schwartz HC: Increased erythropoiesis and elevated erythropoietin in infants born to diabetic mothers and in hyperinsulinemic rhesus fetuses. J Clin Invest 1981, 67(3):637-642.

23. Stonestreet BS, Goldstein M, Oh W, Widness JA: Effects of prolonged hyperinsulinemia on erythropoiesis in fetal sheep. Am J Physiol 1989, 257(5 Pt 2):R1199-1204.

24. Petakov M, Biljanovic-Paunovic L, Jovcic G, Stojanovic N, Todorovic V, Jelkmann W: The influence of acute sterile inflammation on erythropoiesis in rats. Exp Hematol 1998, 26(3):222-227.

25. Zinchuk W, Pronko TP, Lis MA: Blood oxygen transport and endothelial dysfunction in patients with arterial hypertension. Clin Physiol Funct Imaging 2004, 24(4):205-211.

26. Kelm M, Rath J: Endothelial dysfunction in human coronary circulation: relevance of the L-arginine-NO pathway. Basic Res Cardio/ 2001, 96(2):107-127.

27. Singel DJ, Stamler JS: Chemical physiology of blood flow regulation by red blood cells: The role of nitric oxide and S-nitrosohemoglobin Annu Rev Physiol 2005, 67:99-145.

28. Wei $Y$, Liu G, Yang J, Zheng $R$, Jiang $L$, Bao $P$ : The association between metabolic syndrome and vascular endothelial dysfunction in adolescents. Exp Ther Med 2013, 5(6):1663-1666.

29. Facchini FS, Carantoni M, Jeppesen J, Reaven GM: Hematocrit and hemoglobin are independently related to insulin resistance and compensatory hyperinsulinemia in healthy, non-obese men and women. Metabolism 1998, 47(7):831-835

30. Nakanishi N, Suzuki K, Tatara K: Haematocrit and risk of development of Type 2 diabetes mellitus in middle-aged Japanese men. Diabetic Med 2004, 21(5):476-482.

31. Tamariz $\sqcup$, Young JH, Pankow JS, Yeh H-C, Schmidt MI, Astor B, Brancati FL: Blood Viscosity and Hematocrit as Risk Factors for Type 2 Diabetes Mellitus. Am J Epidemio/ 2008, 168(10):1153-1160.

doi:10.1186/1471-2458-13-989

Cite this article as: Wu et al:: Association between erythrocyte parameters and metabolic syndrome in urban Han Chinese: a longitudinal cohort study. BMC Public Health 2013 13:989.

\section{Submit your next manuscript to BioMed Central and take full advantage of:}

- Convenient online submission

- Thorough peer review

- No space constraints or color figure charges

- Immediate publication on acceptance

- Inclusion in PubMed, CAS, Scopus and Google Scholar

- Research which is freely available for redistribution

Submit your manuscript at www.biomedcentral.com/submit
C BioMed Central 